\title{
VIBRATORY CAVITATION EROSION IN AQUEOUS SOLUTIONS
}

\author{
YU-KANG ZHOU* and F. G. HAMMITT
}

Department of Mechanical Engineering and Applied Mechanics, University of Michigan, Ann Arbor, MI 48109 (U.S.A.)

(Received November 11, 1982)

\section{Summary}

Vibratory cavitation erosion tests on AISI-SAE 1018 carbon steel in tap water and in mild $(0.1 \mathrm{M})$ aqueous solutions of $\mathrm{CaCO}_{3}, \mathrm{CaO}, \mathrm{NaHCO}_{3}$ and $\mathrm{NaOH}$ were conducted at a temperature of $80^{\circ} \mathrm{F}\left(27^{\circ} \mathrm{C}\right)$, a double amplitude of $1.38 \times 10^{-3}$ in $(35.1 \mu \mathrm{m})$ and a pressure of $1 \mathrm{~atm}$. For the maximum (150 $\mathrm{min}$ ) test duration the weight loss in tap water (no additive) is the smallest. However, this is not the case for shorter test times. The biggest difference between weight losses among the various solutions is about $10 \%$ $30 \%$, which is somewhat beyond natural data scatter for such vibratory tests. Released gases and also particles may play an important role in the results.

There are three easily distinguishable damage regions for all cavitated surfaces, i.e. generally undamaged rim, central heavily damaged region and transition region, as for most vibratory tests. The relative areas of the three regions are about $53.5 \%, 0.13 \%$ and $46.4 \%$ respectively for the present tests.

The erosion rate and extent of the damaged regions do not depend substantially on the solute tested. The very small area of the heavily damaged central region is presumably due to the relatively low horn amplitude used in these tests. The increase in damage rate with respect to tap water is about $50 \%$ for the maximum test duration.

Surface photographs and scanning electron microscopy photomicrographs (for a test duration of $150 \mathrm{~min}$ ) are presented. Cracks, intercrystalline fractures and single-blow craters are most concentrated in the central region, as would be expected.

\section{Introduction}

Vibratory cavitation is important for both erosion testing and field devices such as diesel engine liners [1 - 3]. Figure 1 illustrates the experimental apparatus used, a $20 \mathrm{kHz}$ piezoelectric transducer with an attached horn.

*Visiting Scholar from the Shanghai Internal Combustion Engine Research Institute, Shanghai, China. 


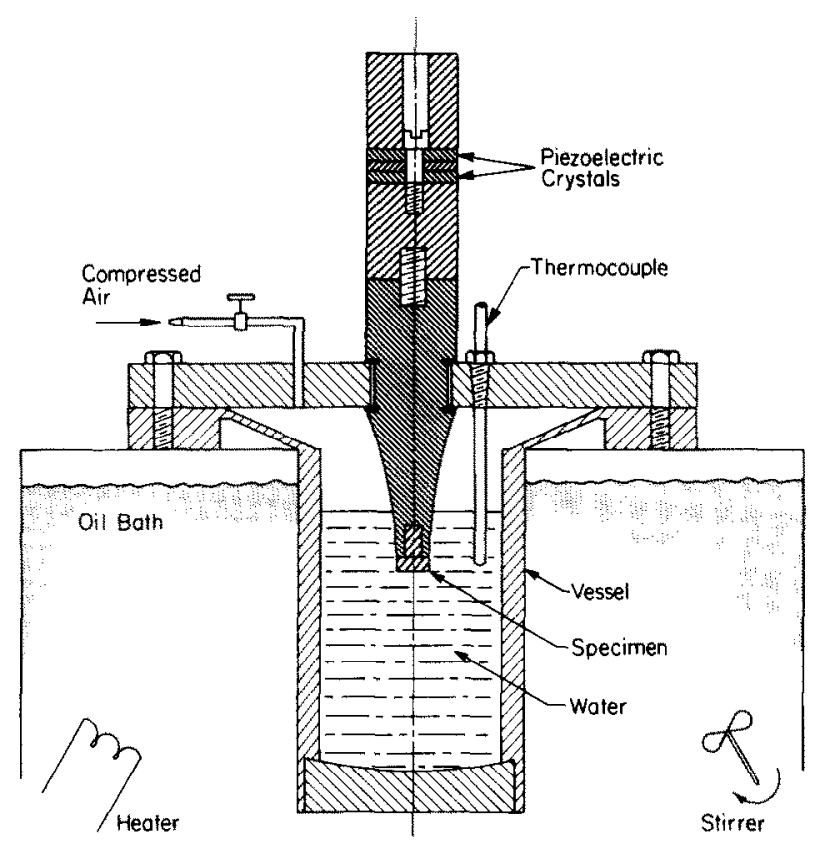

Fig. 1. University of Michigan vibratory system $(20 \mathrm{kHz}$; specimen diameter, $14.3 \mathrm{~mm}$ $(0.562$ in $))$.

Erosion results, for four different fluids and also tap water with no additive, obtained with AISI-SAE 1018 carbon steel at a hom amplitude of $1.38 \times$ $10^{-3}$ in $(35.1 \mu \mathrm{m})$, room temperature and atmospheric pressure are compared. The test specimen diameter is $9 / 16$ in $(14.3 \mathrm{~mm})$, and weight losses are obtained to an accuracy of $\pm 0.1 \mathrm{mgf}$. Before they are weighed the specimens are washed in alcohol and then dried. The test liquids were four mild $(0.1 \mathrm{M})$ aqueous solutions of $\mathrm{CaCO}_{3}, \mathrm{CaO}, \mathrm{NaHCO}_{3}$ and $\mathrm{NaOH}$ in addition to tap water.

The first author has previously investigated erosion of water turbine blades. These had been damaged more heavily by "cavern" (underground) water than by conventional water. The test conditions were only approximately known but, according to chemical analyses, the cavern water contained much more $\mathrm{CO}_{2}$ and also particulate $\mathrm{CaO}$, formed within the cave from $\mathrm{CaCO}_{3}[4]$, than did conventional water.

\section{Experimental results}

The measured data are weight loss and exposure time. Figure 2 shows results for AISI-SAE 1018 carbon steel at $80^{\circ} \mathrm{F}\left(27^{\circ} \mathrm{C}\right)$, an amplitude of $1.38 \times 10^{-3}$ in and atmospheric pressure in the above liquids. A single specimen was tested for each complete curve. Thus five specimens were tested for the full duration $(150 \mathrm{~min})$. Specimens were weighed after each test 


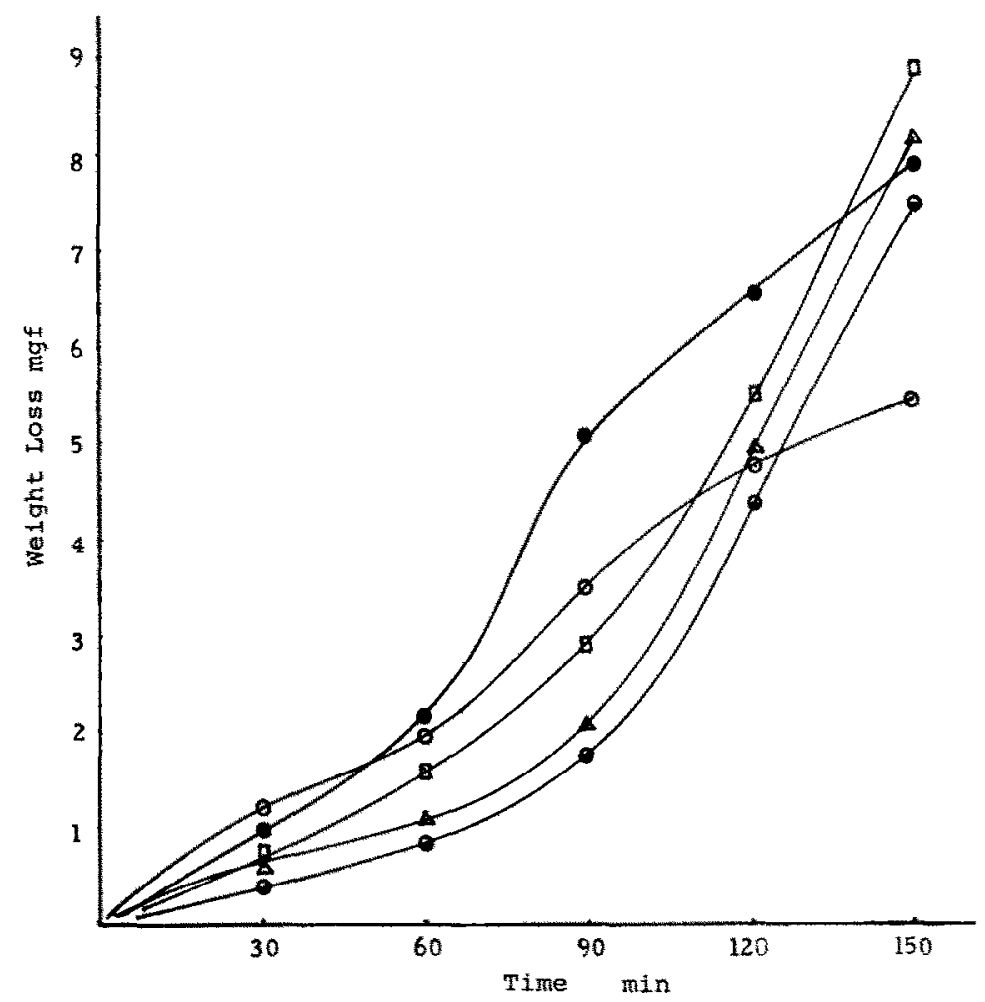

Fig. 2. Curves of weight loss us. test duration for AISI-SAE 1018 carbon steel in tap water and various aqueous solutions (temperature, $80^{\circ} \mathrm{F}$; amplitude, $1.38 \times 10^{-3}$ in; pressure, $1 \mathrm{~atm}$ ): 0 , Ann Arbor tap water; $\bullet, 0.1 \mathrm{M} \mathrm{CaCO}_{3} ; \bullet, 0.1 \mathrm{M} \mathrm{CaO} ; \triangle, 0.1 \mathrm{M} \mathrm{NaHCO}_{3}$; $\square, 0.1 \mathrm{M} \mathrm{NaOH}$.

interval, observed microscopically and scanning electron microscopy (SEM) photomicrographs were taken as desired. Figure 3 shows conventional low magnification (taken at about $2 X$ ) photographs of entire surfaces. Figure 4 (SEM photomicrographs taken at a magnification of 200X) shows the same specimens.

Damage macrostructures are similar for all specimens (Fig. 3 ). In all cases, the central portion is most heavily damaged, as expected, and there is in general (but not always) zero damage for the rim and the specimen sides. Substantial damage occurs also in a "transition region" between these regions. In general, the diameter of a heavily damaged region is only about 0.02 in (about $0.5 \mathrm{~mm}$ ), and the transition region diameter is about 0.375 in (about $9.5 \mathrm{~mm}$ ). The total specimen diameter is 0.562 in $(14.3 \mathrm{~mm})$. Thus the central damage region area is about $0.13 \%$ of the total specimen surface area, the transition region area is about $46.4 \%$ and the rim region is about $53.5 \%$. Maximum damage depths are in the range $(0.008-0.011) \times 10^{-3}$ in $(0.2-0.28 \mu \mathrm{m})$. These damage areas and maximum damage depths are similar to those reported earlier [5] for tests at 2 bar at various amplitudes including the amplitude used here. 


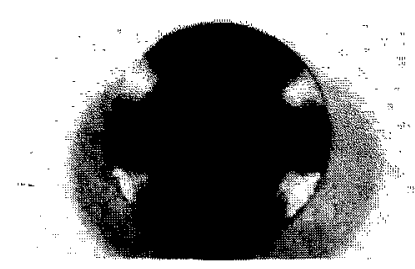

(a)

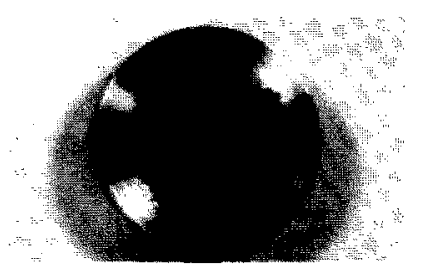

(d)

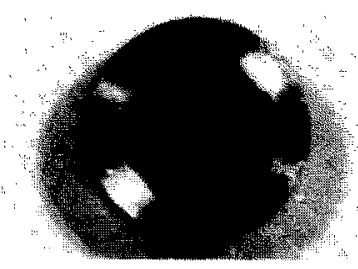

(b)

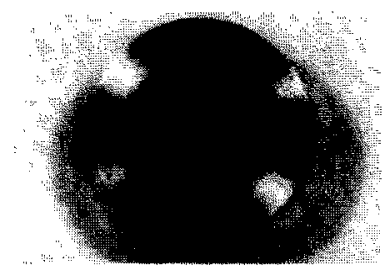

(c)

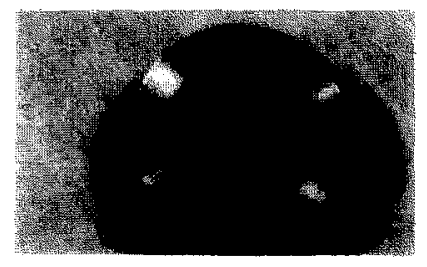

(e)

Fig. 3. Low magnification photographs of AISI-SAE 1018 carbon steel specimens after cavitation in tap water and various aqueous solutions (test duration, $150 \mathrm{~min}$; frequency, $20 \mathrm{kHz}$; temperature, $80^{\circ} \mathrm{F}$; pressure, $1 \mathrm{~atm}$; amplitude, $1.38 \times 10^{-3} \mathrm{in}$ ): (a) Ann Arbor tap water; (b) $0.1 \mathrm{M} \mathrm{CaCO}_{3}$; (c) $0.1 \mathrm{M} \mathrm{CaO}$;(d) $0.1 \mathrm{M} \mathrm{NaHCO}_{3}$; (e) $0.1 \mathrm{M} \mathrm{NaOH}$. (Magnifications, $1.7 \times$.)

The development of the plots of weight loss versus time depends substantially on the solution tested. After the maximum (150 min) test duration the lowest weight loss was for tap water with respect to the four solutions (Fig. 2). However, this was not the case for shorter durations (Fig. 2). In general, there is good consistency between the weight loss curves and the low magnification photographs and also the SEM photomicrographs (Figs. 2 - 4). The larger the weight loss at $150 \mathrm{~min}$ (Fig. 2), the more serious the damage reflected in the photographs (Figs. 3 and 4). Figures $4(\mathrm{a})$ and $4(\mathrm{~b})$ show the same specimen tested in tap water but Fig. 4(a) is from the central damage portion and Fig. 4(b) from the transition region. There are substantial cracks and there is also plastic deformation (single-blow craters), particularly in the central damage portion. However, cracks begin to form (Fig. 4) in the area around the central damage region also. Other detailed results are as follows.

(1) Damage for the surface around the central damage portion is greater for the solutions than for tap water.

(2) Use of the $\mathrm{CaCO}_{3}$ solution (Fig. 4(c)) leads to very obvious cracks in the transition region, and also more serious damage there than for tap water.

(3) Use of the $\mathrm{CaO}$ solution (Figs. 4(d) and 3(c)) leads to a small undamaged area near the heavily damaged central damage point.

(4) Use of the $\mathrm{NaHCO}_{3}$ solution (Fig. 4(e)) leads to a more narrow boundary between the central portion and the transition region and also a much more complex damage pattern in the central damage region. 
(5) Use of the $\mathrm{NaOH}$ solution (Fig. 4(f)) leads to the biggest weight loss for all fluids at the maximum test duration but not for shorter durations.

\section{Discussion}

It might be expected that adding various substances $\left(\mathrm{CaCO}_{3}, \mathrm{CaO}\right.$, $\mathrm{NaHCO}_{3}$ and $\mathrm{NaOH}$ in the present work) to the test water would increase the number and size of the cavitation nuclei. Some solid particle and also $\mathrm{CO}_{2}$ (or other gas) effects might also occur. However, for the first $30 \mathrm{~min}$ of the test weight losses for all solutions were less than for tap water, and for longer intervals they were slightly more in some cases. This reduced damage trend for short intervals might be explained by the release of $\mathrm{CO}_{2}$ (or other gas), especially from $\mathrm{CaCO}_{3}$ and $\mathrm{NaHCO}_{3}$. Any gas should reduce damage by a cushioning effect on bubble collapse (e.g. refs. 1 and 2) but might increase corrosion. Gases which might be generated by the cavitation include $\mathrm{CO}_{2}$, $\mathrm{CO}, \mathrm{O}_{2}$ or $\mathrm{H}_{2}$, depending on the solution. The weight losses for $\mathrm{CaO}$ and $\mathrm{NaOH}$ solutions were also less than for tap water up to about $100 \mathrm{~min}$. Here a gas effect might be due to free oxygen or hydrogen. However, for an accumulated test time of $150 \mathrm{~min}$, the weight loss for tap water is the smallest. Particles which may also be generated should increase erosion. The particle effect may thus be more important for the longer tests.

Three separate damage regions, i.e. the central heavily damaged region, transition region and rim region (Fig. 3), occur in all tests, and also in most vibratory tests, regardless of the fluid. The mechanisms giving such results are clear (e.g. ref. 2) but depend on many test parameters such as amplitude, frequency, $p_{\mathrm{sv}}\left(p_{\mathrm{sv}}=p-p_{\mathrm{v}}\right.$ where $p$ is the static pressure and $p_{\mathrm{v}}$ is the vapor pressure), temperature, fluid and specimen properties. The outer rim is undamaged because of insufficient pressure oscillation there owing to "edge effects", and damage concentrates toward the center because the pressure oscillation is greatest along the specimen axis. For these tests the rim region covers about $53.5 \%$ of the total specimen area for the five liquids tested here. The rim region should increase (e.g. ref. 2 ) for increased $p_{\text {sv }}$ or reduced amplitude. Further work here may verify these trends.

From low magnification photographs (Fig. 3) and microscopic examination the surface contours in the transition region for $\mathrm{CaO}$ and $\mathrm{NaOH}$ solutions are smooth compared with tap water, $\mathrm{CaCO}_{3}$ solution and especially $\mathrm{NaHCO}_{3}$ solution, where the contours become jagged.

In addition, the transition region erosion is not uniformly distributed, and the heaviest damage in the transition region is not generally near the specimen axis. Also, there are often more heavily damaged regions within the generally undamaged outer region than within the transition region (Figs. 3(a) - 3(d)). It is assumed that cavitation bubble collapse should be basically symmetrical about the specimen axis and that the cavitation intensity is not uniform across the transition region.

The boundaries between the three regions are generally very narrow, i.e. the transitions between regions are very sharp. It can be assumed that 

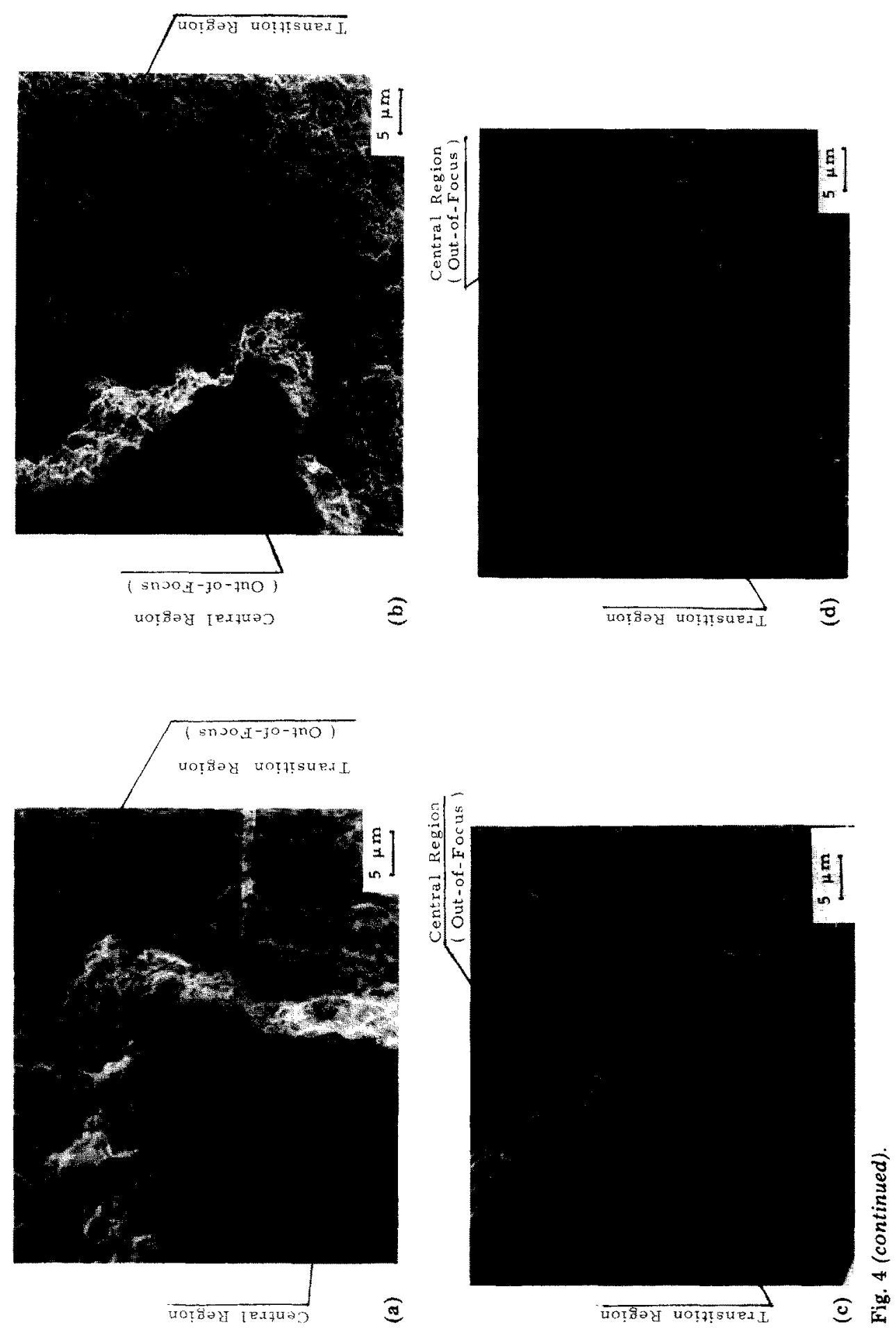

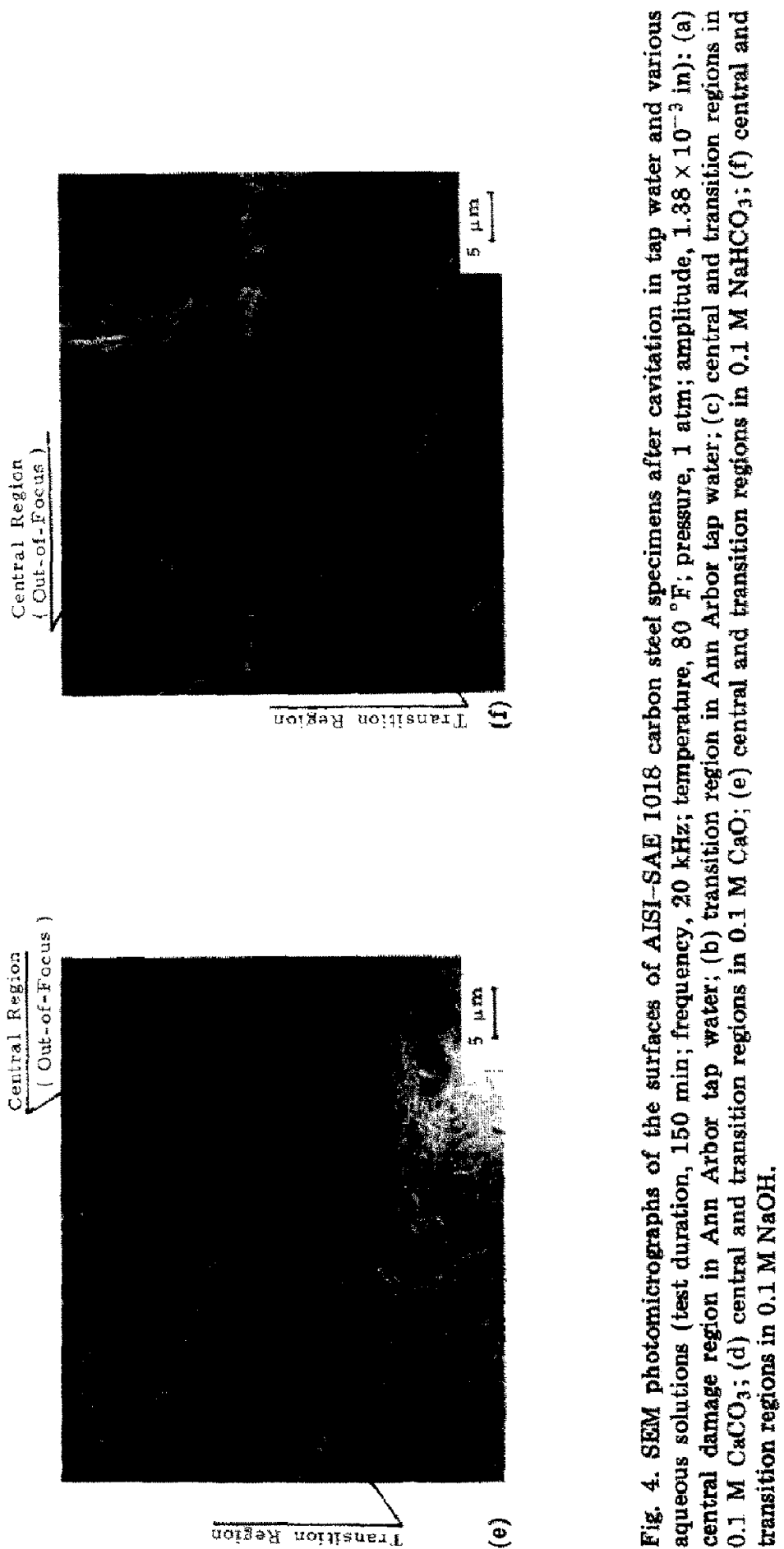
there is no or very little chemical interaction between the specimens (AISISAE 1018 carbon steel) and the solutions, which is not necessarily true for tap water. In the rim region, in general, no corrosion and little erosion were found; this is also true for specimen sides. The weight loss for all solutions was greater than for tap water after the maximum test duration $(150 \mathrm{~min}$ ) but not uniformly so for shorter durations. Thus the solute effects on erosion are highly time dependent.

In the central region there are many cracks, intercrystalline fractures, and single-blow craters (Fig. 4). Mechanical cavitation effects should be the most intense here. Thus solute and gas effects should contribute less in this region. For the present tests, this central region is only about $0.13 \%$ of total specimen surface area. However, damage penetration there is much greater than elsewhere (about $0.2-0.28 \mathrm{~mm}$ ). This strong non-uniformity of damage is believed (e.g. ref. 1) to be increased by the relatively low horn amplitude $\left(1.38 \times 10^{-3} \mathrm{in}\right)$. The effect of horn amplitude and $p_{\mathrm{sv}}$ on this will be investigated later.

\section{Conclusions}

The significant conclusions are as follows.

(1) For the first $50 \mathrm{~min}$ of the test the weight loss for tap water is greater than for aqueous $0.1 \mathrm{M} \mathrm{CaCO}_{3}, \mathrm{CaO}, \mathrm{NaHCO}_{3}$ and $\mathrm{NaOH}$ solutions. However, for a test duration of about $130 \mathrm{~min}$, the weight loss in tap water is the smallest for all test liquids. This trend increases after $150 \mathrm{~min}$ (the maximum test duration). The maximum increase in the weight loss with respect to that in tap water alone for the solutions is about $50 \%$, occurring at the maximum test duration. The difference between the various solutions is relatively small (about $\pm 10 \%$ ).

(2) There are three distinguishable damage regions for such vibratory tests, i.e. undamaged rim, intermediate area and central (heavily damaged) region. In the present tests, the areas of rim region, transition region and central damage region are approximately constant for all liquids (about $53.52 \%$, about $46.35 \%$ and about $0.13 \%$ respectively of the total specimen surface area).

(3) In general, there is neither corrosion nor erosion in the outer rim region or on the specimen sides. This is presumably because $\Delta P$ in these regions is insufficient to cause cavitation. Substantial damage exists in the transition region and heaviest damage in the central region for all liquids, where $\Delta P$ has a maximum value, as expected.

(4) Gases and particles in the liquid, that are generated from the tests, appear to affect the erosion rate in both directions.

\section{Acknowledgments}

Financial support was provided by National Science Foundation Grant ENG 75-2315 and internal University of Michigan funds. 


\section{References}

1 R. T. Knapp, J. W. Daily and F. G. Hammitt, Cavitation, McGraw-Hill, New York, 1970 (also available from Iowa Institute of Hydromechanics Research Press, University of Iowa, Iowa City, IA, 1979).

2 F. G. Hammitt, Cavitation and Multiphase Flow Phenomena, McGraw-Hill, New York, 1980 .

3 F. G. Hammitt, Cavitation erosion: the state of the art and prediction capacity, Appl. Mech. Rev., 32 (6) (1979) 665 - 675.

4 Y.-k. Zhou, A preliminary study of the cylinder liner cavitation erosion of diesel engines, Internal Rep., December 1978 (Shanghai Internal Combustion Engine Research Institute, Shanghai).

5 Y.-k. Zhou and F. G. Hammitt, Vibratory cavitation tests at two bar suppression pressure, DRDA Rep. UMICH 014571-39-I, November 1981 (Division of Research Development and Administration, University of Michigan, Ann Arbor, MI). 